\title{
LA REFORMA DE LAS CLARISAS EN LA CORONA DE ARAGÓN (SS. XV-XVI)
}

\section{Carmen SORIANO TRIGUERO}

Universidad Complutense

\section{Introducción}

En los últimos años diversos grupos de investigadores han renovado el interés por la historia de la Iglesia, conscientes del peso que esta institución y las personas que la componían tenían en la Edad Moderna española. Dentro de ella, las órdenes religiosas han suscitado varios estudios, generalmente locales, que intentan dar nuevas interpretaciones a la historia del contingente más numeroso de eclesiásticos, sobre todo durante los siglos XVI y XVII, insistiendo en sus formas de vida material y espiritual y en las relaciones con otros estamentos e instituciones de la época!.

Ahora bien, analizar las órdenes religiosas en la Modernidad es una tarea ingente, por lo cual es necesario avanzar de lo particular a lo general, comenzando por el conocimiento en profundidad de una orden determinada. En este caso se ha elegido a los franciscanos, tanto en su orden masculina como en la femenina, las clarisas; sin duda, fue la más importante religión mendicante en España y su importancia cualitativa y cuantitativa está fuera de toda duda y algo similar ocurrió con sus hermanas las clarisas. En la actualidad, un grupo de investigadores del Departamento de Historia Moderna de la Universidad Complutense, dirigido por Enrique Martínez Ruiz, está llevando a cabo un amplio programa sobre la orden franciscana con el que se espera renovar los numerosos estudios que existen sobre la misma y aclarar algunas incógnitas tradicionales que permanecen en la historiografía sobre las órdenes religiosas en la España Moderna². Este artículo se inscribe dentro de este programa en su vertiente clarisa.

En los últimos años, al calor de los estudios sobre historia de la mujer, han proliferado las obras sobre la clausura femenina ${ }^{3}$. La orden clariana es la más sig- 
nificativa de todas las femeninas y necesita de un estudio completo que aborden todas sus características religiosas y materiales ${ }^{4}$. Para ello es necesario cubrir dos etapas: la primera consiste en actualizar toda la bibliografía existente y la segunda incluye la introducción directa en los fondos de archivo, tanto en los del Archivo Histórico Nacional, como en los conservados en los claustros aún existentes. El primer paso es bastante sencillo, aunque muy extenso, pues la bibliografía sobre franciscanismo es más abundante de lo que en principio pudiera suponerse. La segunda etapa es mucho más compleja; los fondos documentales se encuentran dispersos por toda la geografía española. Gran parte de los mismos, los procedentes de los conventos afectados por la desamortización del siglo XIX, se hallan centralizados en los citados fondos del Archivo Histórico Nacional; no obstante, éste no es el único centro documental estatal pues, por ejemplo, para el caso de los conventos de clarisas catalano-aragonesas, un volumen considerable de información está depositado en el Archivo de la Corona de Aragón. En uno y en otro caso la característica fundamental de los fondos es su discontinuidad temática y cronológica; en muy extrañas ocasiones encontramos series completas, por lo que la reconstrucción de la vida conventual en todos sus aspectos materiales, religiosos y personales se convierte en una tarea harto dificultosa. Por otro lado, la temática es también muy parcelaria, pues se centra en información económica: ingresos y gastos conventuales, escrituras de censos, juros, propiedades inmuebles, escrituras de dote, etc ${ }^{5}$. Junto a la documentación económica encontramos en muy raras ocasiones registros de hábito y profesas, libros de visitas (por desgracia demasiado escasos) y numerosos pergaminos que suelen contener información jurídica y económica de carácter solemne: breves pontificios, privilegios reales, concesiones especiales, etc ${ }^{6}$.

Ante los problemas que plantea la documentación de los archivos centrales se hace necesaria la investigación en los fondos de los conventos que aún quedan en pie y que previsiblemente poseen series cronológicas y temáticas más completas.

El presente artículo sólo pretende abordar el primer paso esbozado anteriormente, realizando una aproximación a la historia de las clarisas en la Corona de Aragón en los siglos XV y XVI, sin duda los más críticos en la vida de la orden, pues durante ellos se llevaron a cabo las reformas más importantes que iban a caracterizar el devenir de las clarisas durante la Edad Moderna.

\section{Los franciscanos en la Corona de Aragón}

Poco después de haber realizado su viaje a España, con aquel propósito de morir como mártir convirtiendo a los sarracenos y extender su nueva forma de vida basada en la pobreza con fundaciones en Galicia, Castilla, Navarra, Aragón y Cataluña, San Francisco de Asís envió en 1216 a fray Bernardino de Quintaval como director de la "expedición" a la Península Ibérica. Este mandó a fray Juan Perusa y fray Pedro de Saxoferrato a Barcelona, Lérida y Teruel, donde se fundó la ermita de San Bartolomé en 1217; dos años más tarde, fray Juan Parenti funda- 
ba en Zaragoza un convento en el que se celebró el primer capítulo provincial de la Provincia Franciscana de España, en $1220^{7}$. Este es el origen de la presencia franciscana en los territorios de la futura corona aragonesa. En 1233 el capítulo provincial reunido en Soria, dividió la Provincia de España en tres, cada una con su ministro provincial correspondiente: Aragón, Castilla y Santiago. La primera de ellas reunía a Navarra, Cataluña, Valencia, Aragón, Mallorca y Menorca. La expansión de los franciscanos por los territorios aragoneses fue paralela al proceso de reconquista; así por ejemplo, el mismo año 1238 en que Valencia se rinde a las huestes cristianas, se funda el convento de San Francisco, de frailes, y pocos años después uno de monjas franciscanas ${ }^{8}$.

En 1265, la Provincia de Aragón se dividió en siete custodias, debido a los abundantes conventos que la seráfica religión tenía por sus territorios. Este rápido crecimiento no estuvo exento de problemas, especialmente acuciantes en el siglo XIV, por diversos motivos: la epidemia de peste, que tanto afectó a la corona aragonesa diezmando considerablemente su población; la guerra de los dos Pedros y finalmente el nacimiento de los primeros conflictos entre conventuales y observantes, las dos ramas que componían la familia franciscana. La Observancia fue un movimiento de vuelta al primer espíritu de la orden, que afectó a otras comunidades religiosas (agustinos, dominicos, etc.), y que pronto contó con el apoyo de la Corona, al igual que ocurría en Castilla. Mientras tanto, los conventuales se hicieron fucrtes en las ciudades más importantes, apoyados por las oligarquías locales y por el ministro general de la orden de San Francisco, que por estas fechas aún era claustral.

En 1424 nace la primera custodia observante de la Provincia de Aragón, formada por los conventos de Chelva, Manzanera, Sancti Spiritus y Segorbe; es la Custodia de Nuestra Sra. de la Vega, que diez años más tarde se convirtió en Vicaría Provincial Observante, dependiente aún del ministro conventual de Aragón?.

El auge de la Observancia es la tónica que preside la historia del siglo XV, tanto en Aragón como en el resto de Europa con la división en 1443 de la familia observante en dos ramas: la ultramontana y la cismontana. Al mismo tiempo, los conflictos con los conventuales fueron en aumento y se extendieron, como veremos, a los conventos de religiosas clarisas. Los problemas en Aragón fueron mayores que en Castilla, ya que la conventualidad catalano-aragonesa se mantuvo más férrea en sus dominios. El asunto llegó a Julio II que en 1506 prohibió a los observantes adueñarse de más conventos claustrales en la provincia de Aragón, pero como contrapeso absolvía a la Vicaría Observante aragonesa de la obediencia la ministro provincial conventual, colocándola directamente bajo el vicario General Cismontano de la Observancia y facultaba para que se nombrasen tres vicarios observantes, uno por cada reino. La mano de los Reyes Católicos dirigida por Cisneros está detrás de todo este movimiento en favor de la Observancia, tal y como ocurrió en el resto de España ${ }^{10}$. 
El triunfo de la observancia franciscana se produjo en 1517 , cuando en el Capítulo Generalísimo se nombró a un observante como Ministro General de la Orden y se reconoció a esta rama como la legítima representante de la "religión" de San Francisco. Este triunfo supuso la creación de las provincias observantes españolas, antes conventuales y entre ellas la antigua Vicaría aragonesa, que quedó dividida en tres custodias: Valencia, Zaragoza y Mallorca"'.

La historia siguiente es la del paulatino triunfo de la observancia que va aumentando sus claustros, bien por nueva fundación, bien por reforma de las antiguas casas claustrales. Asimismo, la provincia aragonesa comienza a dividirse para mayor operatividad y funcionamiento ante la avalancha de fundaciones franciscanas. La Corona Aragonesa quedará dividida en cuatro provincias: Aragón, Cataluña, Valencia y Mallorca, cada una de ellas con su ministro provincial observante y con sus propios problemas religiosos y jurídicos ${ }^{12}$.

Este es el marco general donde se van a insertar los monasterios de clarisas, las hermanas menores de los franciscanos, y dentro de estos límites van a realizarse las reformas fundamentales que retomaron los preceptos esenciales de la fundadora de la orden, Santa Clara, unidos a nuevos conceptos sobre la clausura y la vida contemplativa femenina.

\section{Las clarisas en la Corona de Aragón}

El domingo de ramos de 1212, Clara Favarone tomaba el hábito y hacía la profesión de manos de San Francisco de Asís, quien le encomendó la tarea de vivir el ideal franciscano dentro de los marcos de la vida contemplativa en el monasterio de San Damián, que él mismo había reconstruido. Las "damianitas" se extendieron con inusitada rapidez por Italia y el resto de Europa y a la muerte de la santa en 1253 se contabilizaban más de cien monasterios con alrededor de 3.000 monjas ${ }^{13}$.

En España, el primer monasterio de damianitas fue el de Santa Engracia de Pamplona ${ }^{14}$ y pronto la Península se convirtió en el principal centro fundador de damas pobres tras Italia. Los territorios cristianos orientales no tardaron en incorporarse a la nueva corriente espiritual femenina y, en 1234 , ya había conventos en Barcelona y Zaragoza; en los años 50, una vez conquistada Valencia, se fundó en la capital del Turia y en Mallorca. Durante el siglo XIV y XV se completó la red fundamental de monasterios clarianos; en total se fundaron 12 conventos en el siglo XIII, 11 en el s-XIV, 7 en el s-XV y otros tantos en el S-XVI. Por provincias franciscanas dentro de los límites de la Corona aragonesa, la distribución de las comunidades religiosas fue la siguiente: 8 en Aragón, 14 en Cataluña. 10 en Valencia, 3 en Mallorca y 2 en la Provincia de Cartagena ${ }^{15}$.

Antes de pasar a analizar la situación clariana que en el siglo XV hizo inevitable la reforma, vamos a exponer la relación completa de los conventos, según los datos aportados por Manuel de Castro. 
CONVENTO

S. Antonio

Sta. Catalina

Sta. Inés

Sta. Inés

Sta. Clara

Sta. Ma Magdalena

La Puridad

Sta. Clara

Sta. Clara

Sta. Clara

Sta. Clara

Ntra. Sra. de la Sierra

Sta. Clara

Sta. Clara

Sta. Clara

Asunción dePedralbes

Sta. Clara

Sta. Clara Cervera

Sto. Cristo de Balaguer Lérida

Sta. Clara

Santa Clara

Sta. Clara

Sta. Clara

Sta. Clara

La Trinidad

Sta. Ma Magdalena

San Juan de la Penitencia

Nira. Sra. del Pasmo de Jerusalén Valencia

Ntra. Sra. de Jerusalén

Encarnación

Sta. Faz

Purísima Concepción

Sta. Isabel

Sta. Isabel

Purísima Concepción

Sta. Clara
LOCALIDAD

Barcelona

Zaragoza

Calatayud

Tarazona

Lérida

Tarragona

Valencia

Palma Mallorca

Castellón de Ampurias

Tortosa

Ciudadela

Montblanch (Tarragona)

Villafranca del Penedés

Gerona

Manresa

Barcelona

Játiva

Puigcerdá

Teruel

Tárrega

Vich

Gandía

Valencia

Inca

Zaragoza

Elche

Alicante

Castellón de la Plana

Barcelona

Oliva

Onda

Alcañiz
AÑO

1234

1234

1240

1240

1241

1248

1250

1256

1260

1267

1285

1298

1308

1319

1322

1326

1326

1344

I347

1360

1366

1369

1383

1428-57

1445

1491

1493

1496

1496

1517

1518

1540

1564

1564

1572

1591
PROV. FRANCISCANA

Cataluña Aragón Aragón

Aragón

Cataluña

Cataluña

Valencia

Mallorca

Cataluña

Cataluña

Mallorca

Cataluña

Cataluña

Cataluña

Cataluña*

Aragón

Valencia

Cataluña

Aragón

Cataluña

Aragón

Cataluña

Cataluña

Valencia

Valencia

Mallorca

Orihuela

Valencia

Aragón

Valencia*

Valencia

Valencia

Cataluña

Valencia

Valencia

Aragón

* En 160 pasó a ser de Carmelitas.

* En 163 pasó a esta provincia, procedente de la de Cartagena. 


\section{Las reformas de las clarisas aragonesas}

Tras el fulgor de la primera expansión clariana, el siglo XIV deja sentir sus críticas características en esta orden femenina. Lo cierto es que su época fundacional tampoco fue nada tranquila ${ }^{16}$, pero los problemas económicos, demográficos y sociales del Trescientos acentuaron la decadencia y condujeron a las monjas a un estado similar al de la orden masculina. Muestra de lo dicho es la casi total traslación de los monasterios de la I a la II Regla, favorecida por el propio cardenal protector franciscano.

A comienzos del siglo XV la situación era caótica; la clausura se incumplía con asiduidad, los conventos contaban con un excesivo número de religiosas que no podían sostenerse, muchos administradores defraudaban sus haciendas, las abadesas se mantenían durante años en el cargo, contraviniendo la Regla y creando un ambiente hostil en el claustro, etc. La lista de faltas podría alargarse y tanto los frailes como las religiosas se daban cuenta de la necesidad de reformar las comunidades.

Así pues, la reforma de la vida clariana provino de dos acciones: primeramente la Observancia, encabezada por los frailes menores y que iba poco a poco ganando camino a la conventualidad y que, como hemos visto, produjo sustanciales cambios en la familia franciscana. En segundo lugar, la propia acción reformista de las religiosas. En el espíritu renovador del siglo XV apareció la figura de Santa Coleta de Corbie (1381-1447) sin la cual es imposible realizar una exposición de la reforma clariana, tanto en Europa como en el más concreto espacio de la corona aragonesa. Santa Coleta renovó la vida clariana imponiendo la I Regla con todo el rigor de la pobreza y colocando a las comunidades de coletinas bajo la jurisdicción de Ministro General de la Orden, en estos momentos un conventual ${ }^{17}$.

En el caso español la reforma se debió, sobre todo, al ambiente general de renovación, más que a una acción directa de los frailes sobre las monjas. Hasta la llegada de Cisneros y su proyecto de reforma clariana, los focos renovadores fueron exclusivamente femeninos: Santa Clara de Gandía, el primer monasterio de coletinas o "descalzas" como se las denominó en la península, y Santa Isabel de los Angeles de Córdoba, foco de la reforma observante bajo la I Regla, curiosamente también denominadas descalzas, pero que no deben confundirse con las anteriores ${ }^{18}$. Por lo que respecta a la acción de los frailes, estuvo vinculada al particular régimen de Santa Clara de Tordesillas, cuyos monasterios se consideraban reformados desde el punto de vista religioso, pero no jurídicamente, pues no obedecían ni a observantes ni a conventuales, sino a un visitador perpetuo propio ${ }^{19}$.

La reforma en los reinos orientales de la península se inició de manos de las coletinas. En 1457 se fundó en Gandía el primer convento de coletinas o descalzas con monjas procedentes del monasterio francés de Leziñán. Aunque existen varias versiones sobre el origen de esta comunidad ${ }^{20}$, lo cierto es que este claustro es el germen de la expansión de una de las ramas con mayor prestigio espiritual en la España moderna.

El rigor en la pobreza, ayuno y vida religiosa eran las características principales de este convento, que obedecía las Constituciones coletinas aprobadas en 1458. 
No obstante, pronto tuvo problemas, pues al depender jurídicamente de los conventuales y estar éstos en proceso de desaparición en España, fue difícil conseguir un confesor que las asistiera espiritualmente. Las monjas solicitaron ayuda al papa, que en 1479 concedió una bula por la que los observantes estaban obligados a asistirlas $\sin$ que tuvieran que abandonar la jurisdicción conventual21. Por otro lado, la estrecha relación que pronto se estableció entre la familia de los Borja, duques de Gandía, y la comunidad, llevó a más de un abuso por parte de algunas de las mujeres de la familia ducal que profesaron en Santa Clara, a pesar de la fama beatísima con que son retratadas por algunos autores 22 . Pero lo que en este caso interesa es conocer la labor reformista llevada a cabo desde Gandía como centro de las clarisas coletinas. En tan sólo cincuenta años, las monjas valencianas fueron las responsables de la fundación o reforma de cuatro monasterios: Gerona, Setúbal (Portugal), Valencia y Castellón de Ampurias ${ }^{23}$. La expansión descalza desde Gandía no se centró sólo en los territorios de la Corona de Aragón, aunque en éstos fue mayoritaria, sino que llegó hasta Castilla y la mismísima Corte. Igualmente, Santa Clara de Gandía fue la responsable indirecta de la fundación o reforma de otros conventos, por así decirlo, "nietos" de las religiosas valencianas. Para comprender la importancia que este claustro tuvo en la reforma de las clarisas, vamos a resumir brevemente un cuadro cronológico de los monasterios reformados durante los siglos XV y XVI directa o indirectamente por Gandía, siguiendo el modelo de IVARS en su obra citada.

Santa Clara de Gandía fue la responsable de la fundación o reforma de los siguientes conventos:

- Purísima Concepción de Gerona (1488); de aquí salieron monjas para fundar Santa Clara de Perpiñán (1500). En 1568 se fundó Santa Isabel de Barcelona, que a su vez fue responsable de la fundación de Ntra. Sra. de la Sierra de Montblanch, en 1594.

- Nombre de Jesús de Setúbal (1496). De él salieron monjas para fundar en Lisboa, y desde aquí a Valladolid en 1550.

- Nuestra Sra. de Jerusalén de Valencia (1497).

- Sta. Clara de Castellón de Ampurias (1505); este claustro fue el encargado de fundar en Tarragona en 1578.

- Sta. Faz de Alicante (1518).

- Casa de la Reina de Logroño (1555): este es el origen del monasterio de Valladolid (1557) que finalmente se trasladó a Madrid con el famosísimo nombre de Las Descalzas Reales (1559), que fue el germen de numerosas fundaciones en el siglo XVII.

El prestigio religioso de la rama coletina, contribuyó a su rápida expansión, apoyada por la nobleza y la monarquía, y los únicos problemas que pudieron surgir fueron jurisdiccionales, a raíz de la extinción del conventualismo en España. La obediencia que las Descalzas debían al Ministro General de la Orden, conventual hasta 1517, provocó varios conflictos, como hemos visto en el caso de las religiosas de Gandía, y como veremos más adelante cuando analicemos las relaciones observantes-conventuales en la Corona de Aragón. 
Las Descalzas fueron un ejemplo claro de reforma femenina desde dentro, mientras que la Observancia (al margen de los monasterios descalzos andaluces) fue un movimiento propiamente masculino que se impuso a las religiosas desde el siglo $\mathrm{XV}$. En el caso de la corona aragonesa, la historia es muy diferente a la castellana, al menos para los conventos franciscanos masculinos, puesto que el conventualismo estaba mucho más arraigado y contaba con el apoyo de las oligarquías locales. La Observancia, no sólo supuso la reforma y fundación de nuevos claustros cuyo objctivo era volver al primitivo espíritu franciscano, sino que acabó convirtiéndose en una pugna con los conventuales por controlar el gobierno general de la orden ${ }^{24}$.

Si para el caso masculino la Observancia en los territorios aragoneses tardó en imponerse tanto religiosa como jurídicamente, algo similar ocurrió con los conventos de clarisas. La reforma atravesó tres períodos claves que vamos a resumir brevemente: la época de los Reyes Católicos, encabezada por la acción de Cisneros y las primeras visitas reformistas a las clarisas catalano-aragonesas; el reinado de Carlos $\mathrm{V}$, en el que se consiguieron pocos avances; y finalmente, la reforma por decreto realizada por Felipe II.

Los primeros intentos de reforma fueron ordenados por Benedicto XII en 1336 , y se caracterizaban por los principios de austeridad y pobreza personal en los conventos de urbanistas; estas disposiciones pontificias no tuvieron buena acogida en Aragón, donde las religiosas estaban acostumbradas a una vida más relajada en mayor contacto con sus familias nobles. Aunque las medidas no se derogaron, lo cierto es que no tuvieron el efecto deseado, y a lo largo del siglo XV la mundanidad, el acaparamiento de riquezas, la inobservancia de la clausura y otros defectos fueron acentuándose, como ya se ha señalado. Al margen del éxito obtenido por el movimiento coletino, habrá que esperar al reinado de los Reyes Católicos para obtener resultados visibles en las comunidades clarianas.

Isabel y Fernando, solicitaron a Alejandro VI, en 1493, plenos poderes para nombrar reformadores que visitasen los monasterios de monjas de sus reinos ${ }^{25}$. Detrás de esta política se hallaba la mano de Cisneros, un franciscano cuyo objetivo era restaurar la Observancia religiosa, no sólo entre los miembros de su misma orden, sino en todas las demás órdenes religiosas, y a través de ella imponer la observancia jurídica. En ese mismo año se nombran los visitadores para Cataluña, que tras algunas dimisiones y ceses acaban siendo Juan Daza y Miguel Fenals ${ }^{26}$. En 1496 fueron nombrados Sancho de Aceves, Martín García y Fray Alfonso de Guadalajara, para la reformas de Aragón, mientras que Antonio de Rosas, Juan Francisco de Avingó y Fray Pedro Bañols, fueron los visitadores para Valencia ${ }^{27}$.

La reforma más importante tuvo lugar en Cataluña, donde se produjeron además los conflictos más significativos. El objetivo de Daza y Fenals era imponer la clausura, suprimir los abusos de riqueza o de poder de la abadesa, y finalmente intentar sujetar a los conventos a la obediencia observante. Al finalizar cada visita, realizaban una serie de ordenaciones que acabaron desembocando en la redacción de unas constituciones para todos los conventos catalanes, en las que, aunque se respetaba la 
segunda regla (mayoritaria en estos conventos), se hacía hincapié en los mismos principios característicos de las constituciones coletinas. Los cuatro apartados básicos de estas ordenaciones y constituciones fueron la clausura, la vida en común, el respeto a los votos y la regla y el cumplimiento de la vida espiritual (oficio, oración y sacramentos) ${ }^{28}$.

Partiendo del hecho común del deplorable estado material de los conventos catalanes, muy afectados por las guerras de Juan II entre 1455-75, durante las cuales incluso fueron utilizados como cuarteles para el ejército, los visitadores se encontraron con situaciones religiosas muy diferentes. Las comunidades más conflictivas fueron San Antonio de Barcelona, Sta. María de Pedralbes y Sta. Clara de Villafranca del Penedés. En San Antonio, los abusos se habían prolongado durante siglos, y aunque había sufrido una visita en 1406 la situación no había mejorado, con el incumplimiento de la clausura y el mantenimiento de escolanas y serviciales dentro del claustro, viviendo en un régimen intermedio entre la clausura y el aseglaramiento, con el consiguiente perjuicio para la buena marcha religiosa de la comunidad.

Daza y Fenals emitieron sus ordenaciones en 1494. La abadesa se negó por dos veces a cumplir las mismas, secundada por la comunidad y la oligarquía barcelonesa. Los visitadores acabaron por deponer a la abadesa y consultaron con los reyes y Roma; un año más tarde presidieron un capítulo que eligió nueva rectora del claustro y en el que todas las religiosas se obligaron a obedecer la Regla de Urbano IV y las ordenaciones emitidas. El tiempo demostró que esta sumisión había sido ficticia, y la costumbre relajada se impuso a la norma y a la ley. La comunidad acudió a Roma y Alejandro VI confirmó unas ordenaciones de 1406, dictadas por fray Tomás Alcina, mucho más benignas que las de los visitadores enviados por Fernando el Católico; de este modo surgió la doble pugna entre los Reyes Católicos y Roma, por un lado, y entre las religiosas y los observantes, por otro. Aquéllas acabaron por abandonar la familia franciscana y adoptaron la regla benedictina en 151329 .

Santa María de Pedralbes se hallaba, desde 1443, bajo tutela conventual. Como en el caso anterior, los visitadores emitieron sus ordenaciones ante las que la abadesa opuso resistencia, por lo que la misma, Sor Violante de Moncada, hubo de ser depuesta. En 1494, y con la aprobación de Fernando el Católico, se dispuso traer religiosas de Santa Clara de Palencia para reformar el claustro, mientras los conventuales eran sustituidos por los observantes en la asistencia espiritual.

En 1498, Sor Violante inició un pleito para apoderarse del convento, con el apoyo de los consellers catalanes; Roma reconoció sus derechos en 1504, excomulgando dos años más tarde a la abadesa palentina, Sor Teresa Enríquez, hecho que debe vincularse a las tirantes relaciones entre el rey católico y la curia romana, que no veía con buenos ojos su excesiva intromisión en el proceso de reforma. Sor violante no regresó al monasterio, pero vivió de sus rentas en las casas que la comunidad poseía en la ciudad. El monarca optó por una solución ecléctica, nombrando a su hija, Sor María de Aragón, abadesa del convento ${ }^{30}$. 
Entre 1494-96 se reformaron los conventos de Santa María de Jerusalén de Barcelona, Sta. Clara de Villafranca, Sta. Clara de Tarragona, Montblanch, Gerona, Castellón de Ampurias, Perpiñán, Balaguer, Puigcerdá, Conques, Vich, Tárrega, Cervera y Tortosa, casi todos sin excesivos conflictos y demostrando una pronta sumisión al espíritu observante.

De esta forma, al finalizar el reinado de los Reyes Católicos, se había dado un primer paso para la imposición de la Observancia. En Valencia, las visitas apenas tuvieron problemas que resolver, puesto que el espíritu coletino ya había dado sus frutos, mientras que en Aragón se vivieron algunas situaciones similares a las de Cataluña, propiciadas por el apoyo de los concejos al conventualismo, como en el caso de Zaragoza.

A pesar del camino andado por sus abuelos, Carlos V tenía que acabar con el conventualismo en la Corona de Aragón, pues en Castilla la labor de Isabel había dado mayores frutos y la Observancia era plenamente mayoritaria.

En Cataluña se emprendió la reforma de las religiosas por vía episcopal, con el fin de corregir abusos e imponer la clausura. La mayor parte de los convento clarianos se libraron de estas visitas, puesto que su vida reformada desde finales del siglo $\mathrm{XV}$ no había sufrido muchas alteraciones ${ }^{31}$. Lo mismo ocurrió en el resto de territorios aragoneses, donde la mayor parte de los conventos clarianos, salvo raras excepciones, se hallaban bajo jurisdicción observante, tal y como lo ordenó el ya citado Capítulo Generalísimo de 1517, en el que ni siquiera las coletinas quedaron fuera de la Observancia jurídica ${ }^{32}$, y antes que éste, el de la reforma observante promulgada en 1509, siendo Vicario Provincial del Aragón, fray Juan de Orós ${ }^{33}$.

En 1565 se promulgó el decreto tridentino cuyos postulados básicos versaban sobre la clausura, desatendiendo algunos abusos seculares como la falta de pobreza o la existencia de cámaras personales en los conventos. Los decretos fucron especialmente mal recibidos en Cataluña, donde el obispo de Barcelona, Guillermo Cassador, decidió emprender la reforma y asegurar la clausura por cualquier medio; si bien están documentados casos de auténtica beligerancia, entre ellos no encontramos a ningún monasterio clariano, más bien todo lo contrario, pues de las comunidades coletinas y damas urbanistas ya reformadas se sacaban monjas para consolidar la reforma en otros claustros. Un año más tarde, en 1566, se daban las órdenes para la extinción del conventualismo mendicante en España, objetivo largamente perseguido por Felipe II y que fue acogido favorablemente por Pío V 34 . El pontífice extendió dos breves que decretaban la reforma de las casas claustrales: el breve Maxime Cuperemus, que ordenaba la reforma y las visitas que debía realizar el obispo diocesano y los superiores observantes de cada orden, y el breve Cum gravissimis de causis, que nos interesa especialmente, pues preceptuaba la reforma de las monjas claustrales de la orden franciscana que se hallaban enclavadas mayoritariamente en los territorios aragoneses ${ }^{35}$.

En 1567 se pusieron en efecto estos dos breves en los reinos orientales; el obispo y el provincial observante se encargaron de visitar los monasterios que aún no 
había aceptado la observancia franciscana. La extinción conventual se llevó a buen ritmo en Aragón y Valencia, incorporando los monasterios por decreto. Como siempre, hubo más problemas en Cataluña, pero lo cierto es que la Observancia acabó imponiéndose y al margen de la regla que siguieran, todas las clarisas quedaron bajo la obediencia de los frailes menores. Sólo quedaron al margen de la Observancia las terciarias, que en muchos casos formaban beaterios que bien dependían de los superiores terciarios, bien de la jurisdicción episcopal, con los consiguientes problemas de interferencias entre unos y otros, sumados a los observantes. En cualquier caso, muchos de estos beaterios de terciarias adoptaron la II Regla como el Monasterio de la Purísima Concepción de Onda (Castellón), que aceptó la regla urbanista en $1572^{36}$. No obstante, hubo casos de beaterios que tras aceptar la regla clariana volvieron a su primaria condición de terciarias con el paso del tiempo, bien por problemas cconómicos, bien porque sus habitadoras no podían soportar una clausura estricta. Así ocurrió con Santa Isabel de Barcelona, que en 1564 abrazó la observancia clariana, pero en 1684 de nuevo se convirtió en una comunidad de terciarias ${ }^{37}$.

De esta forma llegamos al siglo XVII con una comunidad clariana absolutamente reformada y gozando en la Corona de Aragón, al igual que en el resto de España, de una de las mejores famas espirituales entre la clausura femenina. Las clarisas catalanas, aragonesas, valencianas y mallorquinas fueron buen ejemplo de la importancia cualitativa y cuantitativa que esta orden, tanto en su I como II Regla, tuvo en la Edad Moderna. En el Seiscientos, la labor reformista continuaría con visitas trienales a cada monasterio que vigilaban el cumplimiento de las disposiciones tridentinas y, sobre todo, concluyó con la elaboración de unas nuevas constituciones para todas las religiosas franciscanas (de la I y II Regla, Concepcionistas, Recoletas y Terciarias), que constituyen el punto culminante de un proceso reformista que se remonta a finales del siglo XIV y que tendría en el período contrarreformista del Barroco su mayor desarrollo ${ }^{38}$.

\section{NOTAS}

1.- Bucn ejemplo de lo que acabamos de señalar son las recientes obras de ATIENZA LÓPEZ, A. Propiedad, explotación y rentas. el clero regular zaragozano en el siglo XVIII. Zaragoza. 1988; ANDRÉS ROBRES, F. Actitudes económicas de la clerecía culta en el Aniguo Régimen. política financiera del Real Colegio del Corpus Chrisit de Valencia. Valencia. 1986; CALLAHAN, W.J. Iglesia, poder y sociedad en España: 1750-1874 Madrid. 1989; MORGADO GARCÍA, A. Iglesia y sociedad en el Cádiz del siglo XVIII. Cádiz. 1989.

2.- Los estudios más abundantes proceden de los propios franciscanos, que desde 1914 editan la revista sobre estudios franciscanos Archivo Ibero-Americano.

3.- SÁNCHEZ LORA, J.L. Mujeres, conventos y formas de religiosidad barroca Madrid. 
F.U.E. 1988; GOMEZ GARCIA Instituciones religiosas femeninas malagueñas en la transición del siglo XVII-XVIII Málaga. 1987; MARTIN, M.D. Las recogidas: nueva visión de la mística española (1500.1700) Madrid, 1975; VV.AA. Religiosidad femenina: expectativas y realidades (s.VIII-XVIII). Al-Mudaina. Ed. Laya. 1991; TORRES SÁNCHEZ, C. La clausura femenina en la Salamanca del siglo XVII Salamanca. 1991; VALDIVIESO GONZÁLEZ, E. Sevilla oculta: monasterios y conventos de clausura Sevilla. 1987.

4.- Pocas son las obras de conjunto sobre las clarisas, destacando la de OMAECHEVERRÍA, I. Las clarisas a través de los siglos. Madrid. 1972. Sin embargo, es ingente el número de artículos sobre determinados conventos o aspectos locales, casi todos ellos inscritos en el Archivo Ibero-Americano y en otras revistas como Collectanea Franciscana, editada en Roma.

5.- Los libros de registro de la hacienda conventual son relativamente frecuentes, pero en su mayoría carecen de serie cronológica, aportando datos para períodos concretos. Así ocurre, por ejemplo, con el convento de la Purísima Concepción de Alagón (Zaragoza), del que se conservan diversos libros de ingresos, gastos y rentas conventuales entre los siglos XVI y XIX (A.H.N. Clero. Libros 18.554-18.559); lo mismo ocurre con el convento de la Encarnación de Elche, Santa Faz de Alicante, Santa Clara de Calatayud y otras comunidades clarianas.

6.- Los libros de profesas suelen ser poco numerosos, pero cuando se conservan, acostumbran a contener series completas; esto ocurre con Ntra. Sra. del Milagro de Cocentaina, del que se conserva una serie completa de profesas entre 1645 y 1833 (A.H.N. Clero. Libro 282). Por lo que respecta a los pergaminos archivados en el A.H.N., destaca el volumen correspondiente a los conventos de San Juan de Orihuela, con un total de 204 pergaminos entre 1384-1612, y la Puridad de Valencia, que entre 1229-1644 posee 790 documentos. Estos mismos claustros poseen el mayor volumen de legajos procedentes de conventos de la Corona de Aragón conservados en este depósito archivístico.

7.- MARTÍNEZ COLOMER, V. Historia de la Provincia de Valencia de la Regular Observancia de San Francisco. Valencia, 1803. Págs. 1-8.

8.- Ibíd. Págs. 15 ss.

9.- Ibid. Págs. 85-110.

10.- Ibíd. Págs. 156-157. Sobre la reforma de los franciscanos en España y los progresos de la Observancia en la época de los Reyes Católicos, destacan la obras de GARCÍA ORO, J. La reforma de los religiosos españoles en tiempos de los Reyes Católicos Valladolid, 1969. y Cisneros y la reforma del clero español. Madrid. C.S.I.C. 1971.

11.- MARTíneZ COLOMER, V. Op. cit. Pág. 166.

12.- En algunos casos puede incluirse también la Provincia de Cartagena, que básicamente correspondía a Murcia, pero tenía jurisdicción sobre Orihuela.

13.- ELCID, D. Clara de Asís. La hermana ideal de San Francisco. Madrid. B.A.C. 1981. Págs. 60-6I.

14.- RUIZ LARRINAGA, J. "Las clarisas de Pamplona" Archivo Ibero-americano. N ${ }^{0} 5$. Madrid. 1945. Págs. 242-277. SAGÜES AZCONA, P. "Las clarisas de Pamplona y sus reformas en el siglo XVI" Archivo Ibero-americano N33. Madrid. 1973. Págs. 301-368.

15.- CASTRO Y CASTRO, M. de "Monasterios hispánicos de clarisas desde el siglo XIH al XVI" Archivo Ibero-anericano No 49. Madrid. 1989. Págs. 79-122. 
16.- Así lo corrobora el hecho de que en poco más de cincuenta años se aprobaran cinco reglas para dirigir las comunidades: la primera norma de vida dada por San Francisco al monasterio de San Damián; la Regla del Cardenal Hugolino, de 1219; la Regla de Inocencio IV, en 1247; Ja Regla de Santa Clara o Primera Regla, de 1253; y la Regla de Urbano IV o II Regla de 1263. Finalmente, los conventos se dividieron en dos grupos: las clarisas de la I Regla de Sta. Clara, cuya característica era la más absoluta pobreza, defendida por el privilegio de pobreza concedido por Inocencio III en 1215, y las clarisas urbanistas, que seguían la II Regla, cuya característica diferenciadora era que admitía la propiedad en común. En realidad, en el siglo XIV, la mayor parte de las comunidades cran urbanistas y sólo se mantenía un pequeño grupo de "damianitas", encabezado por el primer monasterio. Sobre la historia de las clarisas en su época fundacional destacan, entrc otros, los estudios de IRIARTE, L. Historia Franciscana (Valencia, 1979) y OMAECHEVARRÍA, 1. Las clarisas a través de los siglos (Madrid, 1972).

17.- OMAECHEVERRÍA, I. Op. Cit. Págs. 90-92.

18.- Ibíd. Págs. 101-102. Las descalzas observantes de Córdoba se extendieron casi exclusivamente por Andalucía y su radio de acción no traspasó apenas los límites de esta región.

19.- Sobre el régimen de Tordesillas destaca el artículo de URIBE, A. "Primer ensayo de reforma franciscana en España. La congregación de Santa María la Real de Tordesillas “ Archivo Ibero-americano $\mathrm{N}^{\circ}$ 45. Madrid, 1985 Págs. 217-347.

20.- IVARS, A. "Origen y propagación de las clarisas coletinas o descalzas en España" Archivo Ibero-americano $\mathrm{N}^{\circ} 21$. Madrid, 1924. Págs. 390-410 y en la misma revista AMORÓS, L. "El monasterio de Santa Clara de Gandía y la familia ducal de los Borja" $N^{\circ} 20(1960)$.

21.- AMORÓS, L. Op. Cit. Págs. 480-481.

22.- Así ocurre con la relación expuesta por AMORÓS, L. Ibíd N²1 (1961). En el período fundacional no hubo problemas de este tipo a la luz de los documentos aportados hasta la fecha, pero en 1577 se produce una llamada de atención a las religiosas de Gandía cuardo los frailes tienen que acudir a Gregorio XIll para que envíe un breve para relormar los abusos. Según MARTÍNEZ COLOMER, el cronista de la provincia franciscana de Valencia, las monjas de Gandía "aunque de una vida austera y religiosa, no eran V; estaban sujetas a algunas flaquezas que no pueden separarse externamente de la naturaleza humana. Poseidas unas por la pasión y otras del miedo, hacian sus elecciones de modo que siempre resultaban en favor de Sor Ana Ladrón, por cuyo medio vino a continuar por espacio de 28 años en el puesto de abadesa" (Op. Cit. Págs. 241-242). Tuvieran o no licencia pontilicia, bien es cierto que muchas mujeres de la familia Borja permanecieron demasiados años en el cargo de abadesa, tal y como expone AMORÓS, Op. Cit. Págs. 402-458, pudiendo conducir perfectamente a tensiones y alteraciones dentro del claustro.

23.- AMORÓS, L. Op. Cit. Pág. 484.

24.- El triunfo definitivo de la Observancia, se produjo en 1517 cuando se eligió al Primer Ministro General Observante, al mismo tiempo que la bula the vos de León X cstablecía la primacía de los observantes como únicos y legítimos representantes de la orden, relegando a la conventualidad a un segundo plano y en régimen de paulatina extinción del cual, sin embargo, supo liberarse. GARCIA ORO, J. "La reforma de la órdenes rcligiosas en los siglos XV-XVI", en Historia de la Iglesia en España, Vol. III, 1. BAC. Madrid 1972. Págs. 286-290.

25. - El Papa concedió el permiso a través del breve Exposuerunt nobis. 
26.- AZCONA, T. "Reforma de las clarisas en Cataluña en tiempos de los Reyes Católicos". Collectanea franciscana $\mathrm{n}^{\circ} 27$. Roma, 1957. Págs. 9-10.

27.- OMAEChEverría, I. Op. Cit. Pág. 114.

28.- AZCONA, T. Op. Cit. Págs. 27-28.

29.- Sobre este hecho, véase el artículo de AZCONA, T. "Paso del monasterio de Santa Clara de Barcelona a la Regla Benedictina (1512-1518)" Collectanea franciscana Roma. 1968. Págs. 68-134.

30.- AZCONA, T. "Reforma..." Págs. 15-20.

31.- La reforma carolina se centró en las dominicas, jerónimas y benedictinas y hubo destacados casos de beligerancia, como en el monasterio de las Puellas de Barcelona, Valldoncella, Montealegre y Santa Clara, donde parecía imposible imponer la clausura, por el apoyo que las familias locales y la jerarquía conventual ofrecía a las religiosas, así como el de algunos superiores y teólogos, y por no pocas condescendencias pontificias basadas en la insuficiente base económica de los claustros. GARCÍA ORO, J. Op. Cit. Págs. 303-308.

32.- IRIARTE, L. Op. Cit. Pág. 494.

33.- MARTÍNEZ COLOMER, V. Op. Cit. Pág. 158.

34.- Algunos autores han hablado de "españolización" de la reforma tridentina romana, pues es realmente el monarca hispano quien impone su programa al papa. GARCíA ORO, J. Op. Cit. Págs. 324-336.

35.- Ibid. Págs. 324-325.

36.- CASTRO Y CASTRO, M. Op. Cit. Pág. 116.

37.- Ibidem.

38.- Se trata de las Constituciones Generales para todas las monjas y religiosas sujetas a la obediencia de la Orden de N. P. San Francisco. Roma, 1639. Madrid, 1642. Un breve comentario sobre las mismas ha sido realizado en la tesis de licenciatura de SORIANO, C. El Convento de Santa Clara de Madrid. La vida de las clarisas en la Corte (ss.XVIIXVIII) U.C.M. Madrid. 1993. Págs. 80-104 (inédito). 